\title{
FLORAL AND GEOGRAPHICAL ORIGIN IDENTIFICATION OF HUNGARIAN HONEY WITH ELECTRONIC TONGUE AND CLASSICAL ANALYTICAL METHODS \\ ${ }^{1}$ Fanni Adrienn Koncz, ${ }^{2}$ Zsanett Bodor, ${ }^{3}$ Mahmoud Said Rashed, ${ }^{4}$ Timea Kaszab, ${ }^{5}$ Biborka Gillay, ${ }^{6}$ Zoltan Kovacs, ${ }^{7}$ Csilla Benedek
}

\begin{abstract}
${ }^{1}$ Department of Physics and Control, Faculty of Food Science, Szent Istvan University, 14-16 Somloi str., 1118 Budapest, Hungary, konczfanni54@gmail.com

${ }^{2}$ Department of Dietetics and Nutrition Sciences, Faculty of Health Sciences, Semmelweis University, 17 Vas str., 1088 Budapest, Hungary, arscube@gmail.com

${ }^{3}$ Department of Physics and Control, Faculty of Food Science, Szent Istvan University, 14-16 Somloi str., 1118 Budapest, Hungary, mahmoudsaidrashed88@gmail.com

${ }^{4}$ Department of Physics and Control, Faculty of Food Science, Szent Istvan University, 14-16 Somloi str., 1118 Budapest, Hungary, kaszab.timea@etk.szie.hu

${ }^{5}$ Department of Physics and Control, Faculty of Food Science, Szent Istvan University, 14-16 Somloi str., 1118 Budapest, Hungary, gillay.biborka@etk.szie.hu

${ }^{6}$ Department of Physics and Control, Faculty of Food Science, Szent Istvan University, 14-16 Somloi str., 1118 Budapest, Hungary, kovacs.zoltan3@etk.szie.hu
\end{abstract}

${ }^{7}$ Department of Dietetics and Nutrition Sciences, Faculty of Health Sciences, Semmelweis University, 17 Vas str., 1088 Budapest, Hungary, benedek.csilla@se-etk.hu

\begin{abstract}
Honey has been widely used for health care and as sweetener since the ancient times. Due to its great nutritional value and its high price, honey is one of the most adulterated products on the market. Therefore, there is a need to develop new quick measurement methods to recognize the adulteration. Almost 80 authentic honey samples of different floral and geographical origins were collected for our experiments, focusing mainly on Hungarian honey. Various analytical methods were used for the determination of the nutritional values of the honey samples, e.g. antioxidant capacity, polyphenol content, ash content, $\mathrm{pH}$, conductivity, etc. These measurements aim to complete the scarcely available data on Hungarian honeys. In addition, we determined sensory properties by color and electronic tongue analyses. Electronic tongue enables easy sample preparation and results are delivered in a short time. Evaluating the results by different multivariate statistical methods, determination of the floral and geographical origin of the samples was possible based on the results of the electronic tongue measurements. The results achieved with these classifications methods have proven by building up a robust database electronic tongue can be used for origin authentication of domestic honey samples.
\end{abstract}

Keywords: Hungarian honey, chemometrics, authentication, electronic tongue

\section{INTRODUCTION}

As a sweetener with high nutritional value, honey has been used since the ancient times. It is rich in biologically active compounds such as vitamins, minerals and antioxidants, organic acids, possessing 
specific sensory qualities at the same time. As one of the important honey producers, Hungary is wellknown for its high-quality products, considered often as reference standards [1]. Due to its qualities honey is present on the market as an important, high-priced product, which has become one of the most adulterated ones. Honey counterfeit methods range from simple addition of sugar syrups to mislabeling of floral and geographical origin. Although a wide variety of instrumental analytical methods and their combination have been developed to detect adulteration, these are often expensive and time-consuming, needing highly qualified operator [2].

Due to these limiting conditions in honey analysis, there is a continuous need for relatively cheap and simple techniques. Beside classical analytical parameters, antioxidant profile and flavor analysis can be good candidates for honey differentiation [3][4][5].

Electronic tongue can be also used as a potential method for identification of honey samples by botanical or geographical origin[6]. Various statistical analysis methods - e.g. discriminant analysis (DA) or principal component analysis (PCA) - can be employed successfully to achieve a proper classification of honeys based on the parameters measured.

\section{MATERIALS AND METHODS}

\subsection{Honey samples}

In this study 77 honey samples of different floral and geographical origin were analyzed. To ensure authenticity, honeys were collected mainly from the producers but we have some also procured some commercial products for comparison. All of the 60 Hungarian honeys are from honey producers, including samples of acacia $(n=18)$, false indigo $\operatorname{bush}(n=4)$, honeydew $(n=5), \quad$ pine $(n=2)$, chestnut $(n=4)$, buckwheat $(n=1)$, linden $(n=9)$, linden-chestnut $(n=1)$, raspberry $(n=2)$, milk thistle $(n=1), \operatorname{mustard}(n=1)$,

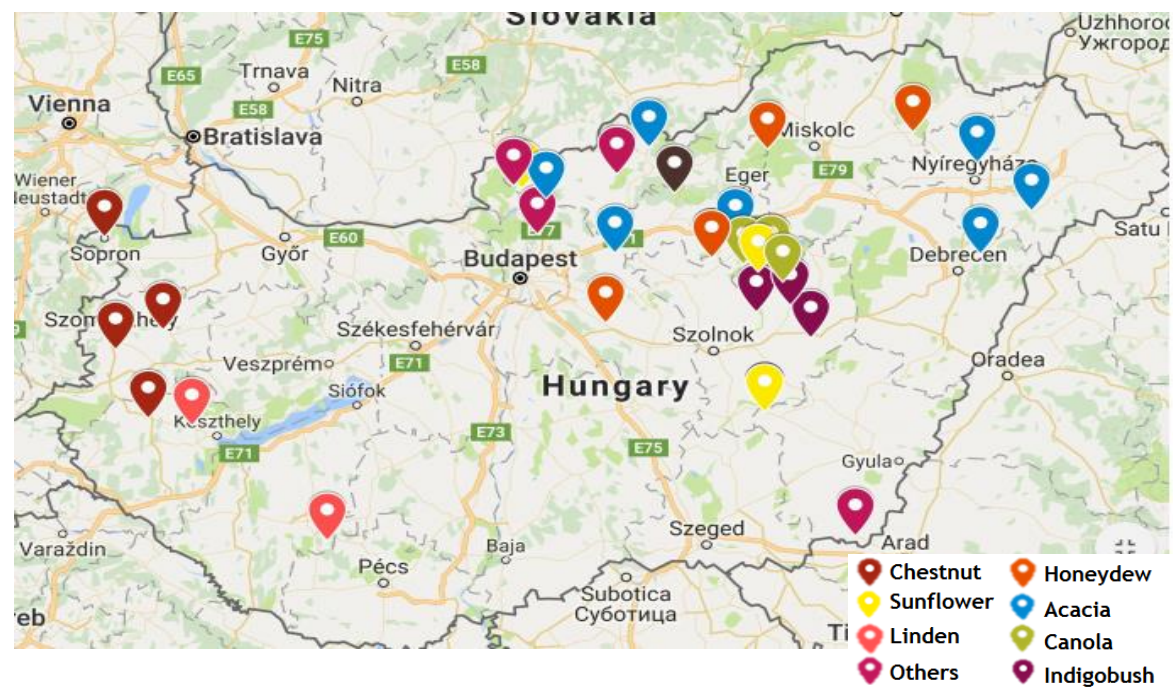

Figure 1. Geographical origin of Hungarian honey samples 
sunflower( $(n=6)$, canola( $(n=4), \quad$ canola-fruit $(n=2), \quad$ canola-linden $(n=1), \quad$ bear's $\operatorname{garlic}(n=1)$, meadow sage $(n=1)$, silkgrass $(n=4)$ and multiflora $(n=10)$ honeys. We also tested honey samples from different European and non-European origins. Hungarian honeys were collected from different parts of Hungary (Fig. 1). The samples were stored at room temperature.

\subsection{Methods}

\subsubsection{Physicochemical properties}

Classical honey analytical parameters (ash, $\mathrm{pH}$, conductivity, total water soluble matter by refractometry) were determined according to the International Honey Committee [7].

\section{Ash content}

Three to seven grams of honey sample was measured to a porcelain jars and two drops of olive oil were given in each jar. Then the samples were pre-combusted with a gas burner and put in the electric furnace at $600{ }^{\circ} \mathrm{C}$ until constant weight was reached. 2 parallel measurements were applied.

\section{pH determination}

$1.333^{\circ} \mathrm{g}$ honey sample was weighted in and dissolved in $10 \mathrm{ml}$ carbon dioxide-free distilled water and measured with a pH meter. One sample had 3 parallel measurements.

\section{Electrical conductivity}

An amount of honey, equivalent to $20.0 \mathrm{~g}$ anhydrous honey, was dissolved in distilled water, then it was transferred quantitatively to a $10 \mathrm{ml}$ volumetric flask and made up to volume with distilled water. The electrical conductivity of the solution was measured. 3 measurements were applied per sample.

\section{Refractometry}

Honeys were also analyzed using an Abbé refractometer to read their refractive index which provides information about the dry matter content of the sample using the tables of the International Honey Commission (Bogdanov, 2002). 2 parallel measurements were applied.

\subsubsection{Total polyphenol content and antioxidant capacity}

\section{Sample preparation}

$\sim 1 \mathrm{~g}$ of honey sample was diluted 10 times with distilled water and the solution used for antioxidant measurements (honey sample solution).

Spectrophotometric measurements were performed on a Thermo Helios Alpha UV-VIS spectrophotometer ( \pm 0.001 units of absorbance), using cells of $1 \mathrm{~cm}$ path.

\section{Total polyphenol content}

Total polyphenol content (TPC) was determined by the Folin-Ciocalteu method, following a procedure adapted from [8]. For the test $1 \mathrm{ml}$ of the honey sample solution was put in a test tube, and $7.5 \mathrm{ml}$ distilled water was added. Then $0.5 \mathrm{ml}$ of the Folin-Ciocalteu reagent was given to each tube and after 3 
minutes $1 \mathrm{ml} \mathrm{Na} \mathrm{CO}_{3}$ solution was added. Absorbances were read at $750 \mathrm{~nm}$ after a 30 -minutes incubation period in the dark. Results were expressed as mg equivalents of gallic acid (GAE) per $100 \mathrm{~g}$ honey.

\section{FRAP assay}

In FRAP experiments, the reduction power of honeys was estimated according to the procedure described by Benzie \& Strain[9]. Briefly, the freshly prepared FRAP reagent contained $25.0 \mathrm{ml}$ of $300 \mathrm{mM}$ acetate buffer, $2.5 \mathrm{ml}$ of $10 \mathrm{mM}$ TPTZ solution in 40mM HCl, $2.5 \mathrm{ml}$ of $20 \mathrm{mM}$ iron (III) chloride solution. For the measurements $500 \mu \mathrm{l}$ honey stock solution was given to $15 \mathrm{ml}$ of FRAP reagent, rigorously shaken, incubated at $37{ }^{\circ} \mathrm{C}$ for an hour and then measured at $653 \mathrm{~nm}$, against a blank. Results were reported as $\mu \mathrm{mol}$ ascorbic acid equivalent (ASE) /g honey.

\subsubsection{Electronic tongue}

The electronic tongue is designed to recognize and analyze the dissolved compounds in liquid samples. An $\alpha$ Astree electronic tongue (ET) [10] was applied to identify the botanical and geographical origins of honeys, The ET consist a sensor array with seven potentiometric sensors (ZZ, JE, BB, CA, GA, $\mathrm{HA}$ and JB) developed for food applications and an $\mathrm{Ag} / \mathrm{AgCl}$ reference electrode. 9 measurements were applied per sample, with 3 repeating.

\section{Sample preparation}

10 grams of each honey sample were measured and diluted in a $100 \mathrm{ml}$ volumetric flask with distilled water. The samples were tested at room temperature.

\section{Statistical analysis}

Multivariate statistical methods such as principal component analysis (PCA) and discriminant analysis (DA) were applied to evaluate the results of the electronic tongue. PCA enables recognition of the main patterns in the measurement data[11]. DA is a data-analytic tool for classification maximizes the between-class scatter and minimize the within-class scatter. ). R-project was applied for data evaluation.

\section{RESULTS AND DISCUSSION}

\subsection{Results of the classical analytical methods}

These indicators, obtained in the preliminary measurements of the honey samples are used for characterization of honeys and interpretation of the results of electronic tongue.

\section{Total polyphenol content and antioxidant capacity}

The polyphenols and antioxidant capacity are important properties of honey.

According to the literature, similar values were found in honeys from the same floral origin, but significant differences were shown between honeys from distinct botanical sources. Low concentrations of polyphenols were measured in acacia and canola honeys (average: $5.0 \mathrm{mg} \pm 0.5 \mathrm{GAE} / 100 \mathrm{~g}$, respectively $5.8 \pm 0,6 \mathrm{mg} \mathrm{GAE} / 100 \mathrm{~g}$ ). Higher values were found in honeydew and chestnut honeys (average: $16.7 \pm 1.1$ 


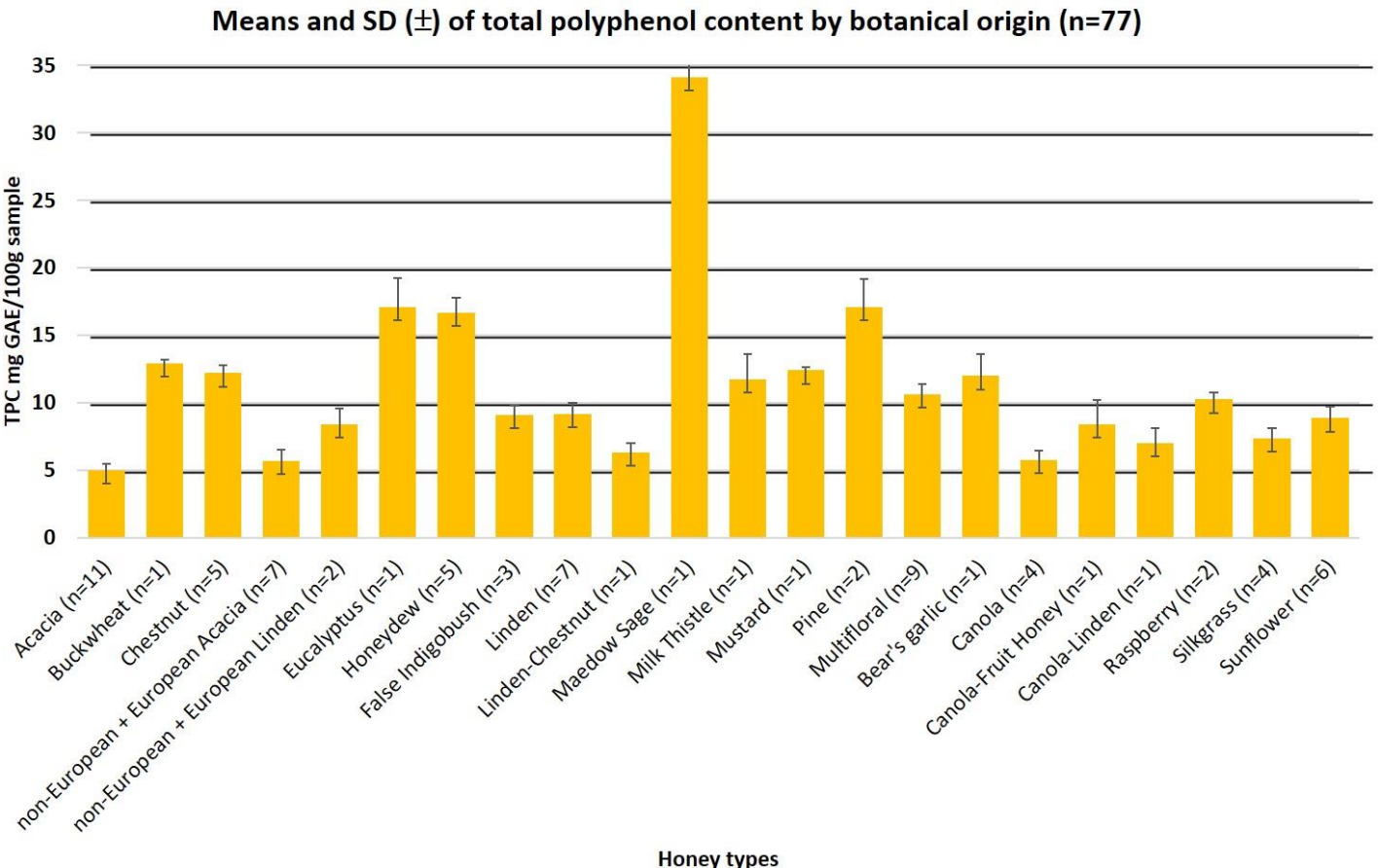

Figure 2. Average of total polyphenol content by botanical origin

mg GAE/100g, respectively $12.2 \pm 0.6 \mathrm{mg} \mathrm{GAE} / 100 \mathrm{~g}$ ) (Fig. 2) Similar trends were observed in FRAP antioxidant capacity results.

\section{Physicochemical properties}

Target physicochemical parameters used for honey characterization. The $\mathrm{pH}$ of the analyzed honeys was in the range 3.6-4.9, while the electrical conductivity was over $156 \mu \mathrm{S} / \mathrm{cm}$ in all samples, the highest values were detected in honeydew honeys (over $1000 \mu \mathrm{S} / \mathrm{cm}$ ), while acacia and canola honeys were on the other end. The ash content, which is an indicator of the mineral content, was between the range of 0.036$0.918 \%$, which correlates well with electrical conductivity values for the different types of honeys. As regards total water-soluble matter, the lowest values were found for milk thistle honey (78.8\%) and highest in buckwheat honey $(84.8 \%)$.

\subsection{Results of the electronic tongue measurement}

\subsubsection{Principal component analysis results}

The PCA results are shown in Fig. 3, the first three principal components explain 96,84\% of the total variance. The data points of different floral origin honeys show some separation, acacia and linden honeys presents the two major groups. 

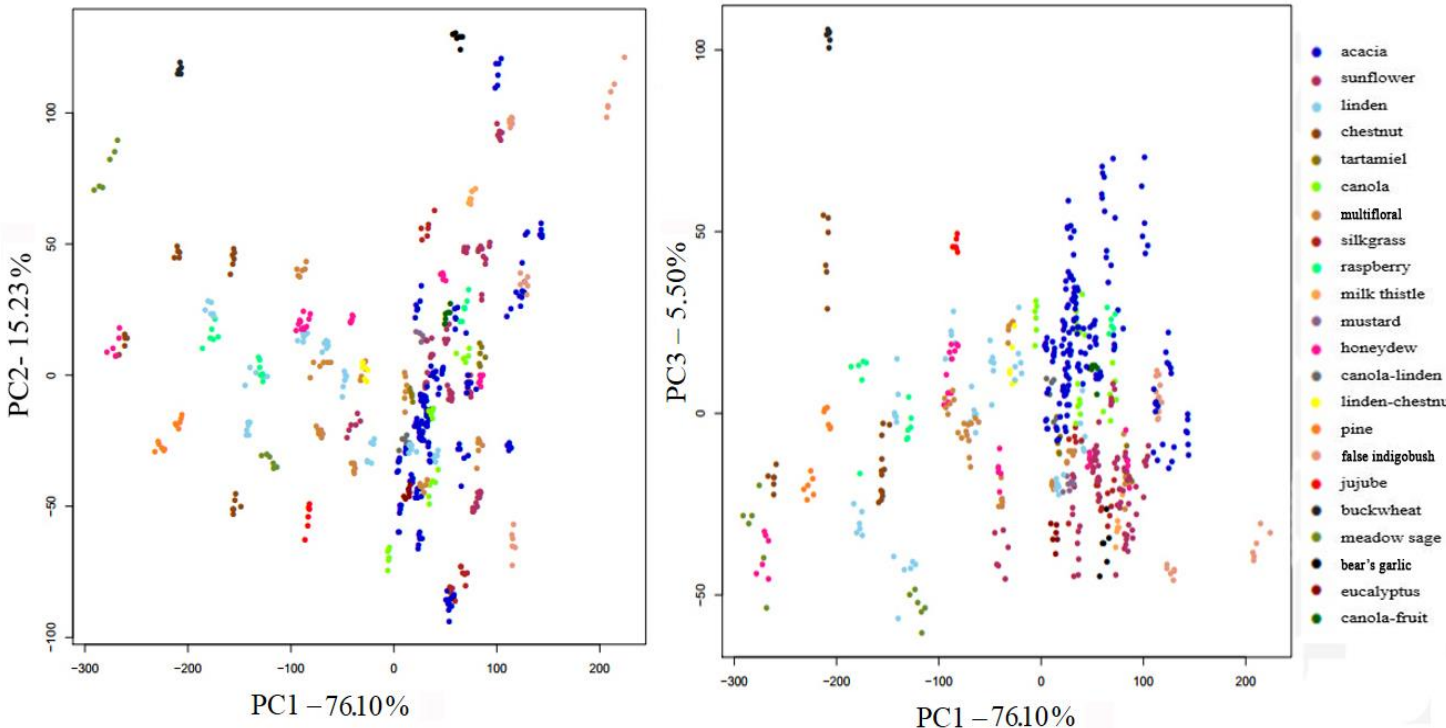

Figure 3. PCA plots of honey samples from different floral origins calculated

based on the results of electronic tongue

Data points of several honeys are separated from the others, these samples also have higher values of polyphenol content and electrical conductivity.
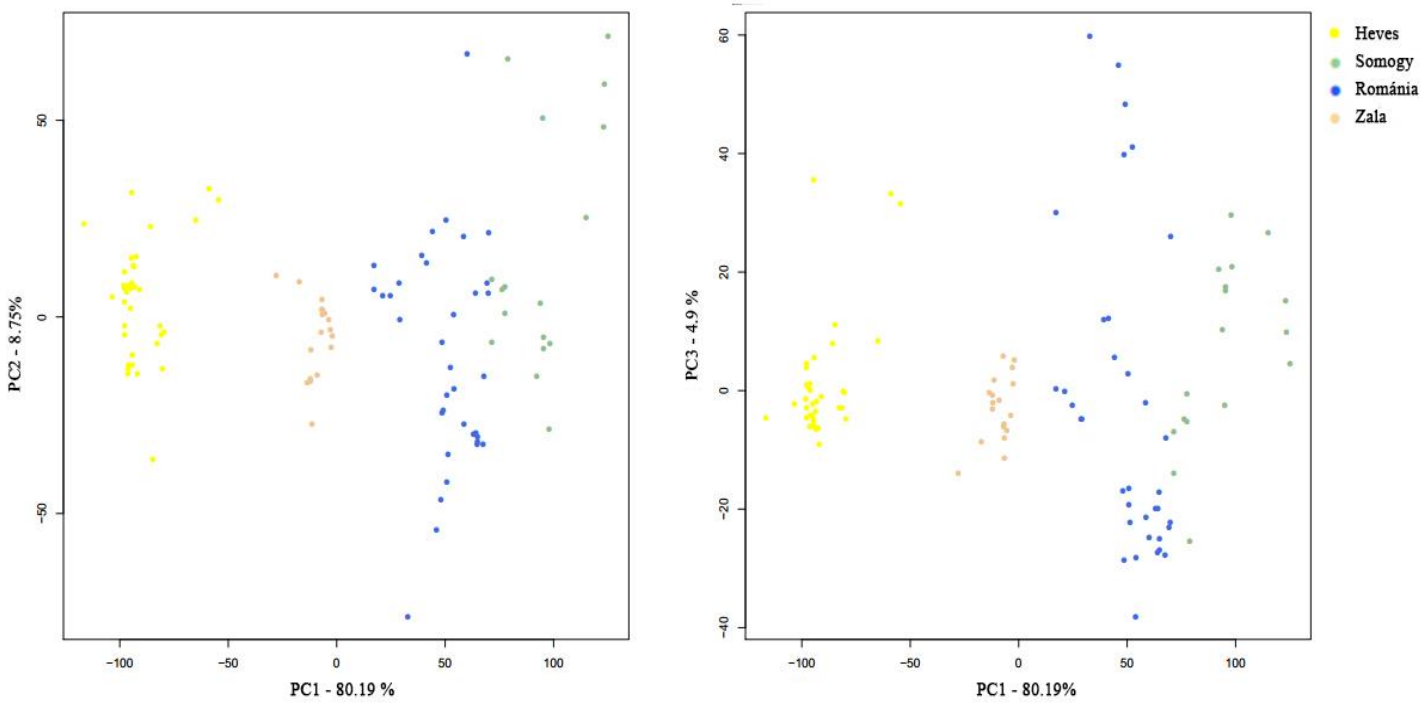

Figure 4. PCA plots for the linden honey samples from different geographical origins based on the electronic tongue 
If the floral and the geographical origins were analyzed together, then the samples with different geographical, but the same floral origin were close to each other. Because of the dominance of the floral origin, the geographical origin of the samples was evaluated per floral groups. Results of PCA (Fig. 4) show that linden honey samples originating from different geographical origins present good separation.

\subsubsection{Discriminant analysis results}

Classification models were built for floral and geographical origin identification, respectively. Results of the achieved discrimination performance of the DA model for floral identification in training and cross-validation is shown in Table 1 . The model correctly classified linden, sunflower, canola and silkgrass honey samples and presented recognition and prediction abilities of $96.3 \%$, respectively for acacia samples misclassifying $3.7 \%$ as belonging to the group of canola samples.

The geographical origin based classification was also accurate (for example average recognition and prediction abilities were found for linden 100\%), when the places of geographical origin of the honey samples were far enough from each other and climatic conditions were different.

Table 1. DA results for discriminating honey floral origin using electronic tongue

\begin{tabular}{|c|c|c|c|c|c|}
\hline \multicolumn{6}{|c|}{ MODEL BUILDING (\%) } \\
\hline & Acacia & Linden & Sunflower & Canola & Silkgrass \\
\hline Acacia & 96.30 & 0.00 & 0.00 & 0.00 & 0.00 \\
\hline Linden & 0.00 & 100.00 & 0.00 & 0.00 & 0.00 \\
\hline Sunflower & 0.00 & 0.00 & 100.00 & 0.00 & 0.00 \\
\hline Canola & 3.70 & 0.00 & 0.00 & 100.00 & 0.00 \\
\hline Silkgrass & 0.00 & 0.00 & 0.00 & 0.00 & 100.00 \\
\hline \multicolumn{6}{|c|}{ MODEL VALIDATION (\%) } \\
\hline & Acacia & Linden & Sunflower & Canola & Silkgrass \\
\hline Acacia & 96.30 & 0.00 & 0.00 & 0.00 & 0.00 \\
\hline Linden & 0.00 & 100.00 & 0.00 & 0.00 & 0.00 \\
\hline Sunflower & 0.00 & 0.00 & 100.00 & 0.00 & 0.00 \\
\hline Canola & 3.70 & 0.00 & 0.00 & 100.00 & 0.00 \\
\hline Silkgrass & 0.00 & 0.00 & 0.00 & 0.00 & 100.00 \\
\hline
\end{tabular}




\section{CONCLUSION}

Authentic Hungarian honeys were found to present high antioxidant activities, similarly to those described in the literature for other countries. This supports the high nutraceutical value of honey and provides new data which are lacking at the present for domestic products.

Special honeys like bear's garlic, chestnut or jujube were clearly separated from the rest of the samples based on the results of electronic tongue. The major groups such as Acacia and Linden presented also distinct patterns in the PCA maps. The results of classification showed honey samples can be differentiated according to their floral source with high accuracy. Moreover, electronic tongue enables estimation of geographical origin within the Carpathian basin, as shown for linden honeys.

The possible applicability of the electronic tongue as a single analytical tool has been proven to be useful in botanical and geographical classification of honeys.

Further exploration of the potential of this technique in classification and authentication of honeys is planned by completing the statistical evaluations with data resulting from other widely available measurement techniques, e.g. near infrared spectrophotometry (NIR), or combining with classical analytical parameters.

\section{ACKNOWLEDGEMENT}

This paper was supported by the János Bolyai Research Scholarship of the Hungarian Academy of Sciences.

This paper was supported by the ÚNKP-16-2-1 New National Excellence Program of the Ministry of Human Capacities. 


\section{REFERENCES}

[1] Czipa, N. (2010). Különböző eredetủ mézek összehasonlító vizsgálata és a gyártmánykialakítás hatása a minőségre. PhD. thesis, University of Debrecen

[2] Spiteri, M., Jamin, E., Thomas, F., Rebours, A., Lees, M., Rogers, K. M., \& Rutledge, D. N. (2015). Fast and global authenticity screening of honey using ${ }^{1} \mathrm{H}-\mathrm{NMR}$ profiling. Food Chem, 189, 60-66. doi: http://dx.doi.org/10.1016/j.foodchem.2014.11.099

[3] Bougrini, M., Tahri, K., Saidi, T., El Alami El Hassani, N., Bouchikhi, B., \& El Bari, N. (2016). Classification of Honey According to Geographical and Botanical Origins and Detection of Its Adulteration Using Voltammetric Electronic Tongue. Food Analytical Methods, 9(8), 2161-2173. doi: http://dx.doi.org/10.1007/s12161-015-0393-2

[4] Cimpoiu, C., Hosu, A., Miclaus, V., \& Puscas, A. (2013). Determination of the floral origin of some Romanian honeys on the basis of physical and biochemical properties. Spectrochim Acta A Mol Biomol Spectrosc, 100, 149-154. doi: 10.1016/j.saa.2012.04.008

[5] Jose, M. A.-S., Sara, T., Stefania, R., Alexis, V., \& Maurizio, B. (2009). Methodological Aspects about Determination of Phenolic Compounds and In Vitro Evaluation of Antioxidant Capacity in the Honey: A Review. Current Analytical Chemistry, 5(4), 293-302. doi: http://dx.doi.org/10.2174/157341109789077768

[6] Sousa, M. E. B. C., Dias, L. G., Veloso, A. C. A., Estevinho, L., Peres, A. M., \& Machado, A. A. S. C. (2014). Practical procedure for discriminating monofloral honey with a broad pollen profile variability using an electronic tongue. Talanta, 128, 284-292. doi: http://dx.doi.org/10.1016/j.talanta.2014.05.004

[7] Bogdanov, S., Martin, P., \& Lullmann, C. (2002). Harmonised methods of the international honey commission. Swiss Bee Research Centre, FAM, Liebefeld.

[8] Singleton, V. L., \& Rossi, J. (1965). Colorimetry of Total Phenolics with PhosphomolybdicPhosphotungstic Acid Reagents. Am. J. Enol. Vitic., 16(3), 144-158. doi: citeulike-article-id:7170825

[9] Benzie, I. F. F., \& Strain, J. J. (1996). The Ferric Reducing Ability of Plasma (FRAP) as a Measure of “Antioxidant Power": The FRAP Assay. Analytical Biochemistry, 239(1), 70-76. doi: http://dx.doi.org/10.1006/abio.1996.0292

[10] AlphaM.O.S. (2003). aAstree electronic tongue user manual.

[11] Steinbach, M., Kumar, V., \& Tan, P. (2011). Bevetés az adatbányászatba (pp. 487). Budapest: Panem Könyvkiadó Kft. 